Discussion Paper No. 777

\title{
MARKET COMPETITION, R\&D AND FIRM PROFITS \\ IN ASYMMETRIC OLIGOPOLY
}

\author{
Junichiro Ishida \\ Toshihiro Matsumura \\ Noriaki Matsushima
}

May 2010

The Institute of Social and Economic Research

Osaka University

6-1 Mihogaoka, Ibaraki, Osaka 567-0047, Japan 


\title{
Market Competition, R\&D and Firm Profits in Asymmetric Oligopoly*
}

\author{
Junichiro Ishida ${ }^{\dagger}$ \\ Institute of Social and Economic Research, Osaka University \\ Toshihiro Matsumura ${ }^{\ddagger}$ \\ Institute of Social Science, University of Tokyo \\ Noriaki Matsushima ${ }^{\S}$ \\ Institute of Social and Economic Research, Osaka University
}

May 24, 2010

\begin{abstract}
We investigate a Cournot model with strategic R\&D investments wherein efficient low-cost firms compete against less efficient high-cost firms. We find that an increase in the number of high-cost firms can stimulate R\&D by the low-cost firms, while it always reduces $\mathrm{R} \& \mathrm{D}$ by the high-cost firms. More importantly, this force can be strong enough to compensate for the loss that arises from more intense market competition: the low-cost firms' profits may indeed increase with the number of high-cost firms. An implication of this result is far-reaching, as it gives low-cost firms an incentive to help, rather than harm, high-cost competitors. We relate this implication to a practice known as open knowledge disclosure, especially Ford's strategy of disclosing its know-how publicly and extensively at the beginning of the 20th century.
\end{abstract}

JEL classification: L13, O32, M21

Key words: competition, oligopoly, R\&D, heterogeneity, entry.

${ }^{*}$ An earlier version of this paper was circulated under the title "When Market Competition Benefits Firms." We would like to thank Masahiro Ashiya, Naoko Nishimura, Dan Sasaki, Nicolaos Vettas, Wen Zhou, seminar participants at CPRC, EARIE2009, GRIPS, Kwansei Gakuin University, Niigata University, Osaka Prefecture University, Shinshu University, two anonymous referees and the editor, Patrick Legros, for their helpful comments and suggestions. We gratefully acknowledge financial support from Grant-in-Aid from the Japanese Ministry of Education, Science and Culture. Needless to say, we are responsible for any remaining errors.

${ }^{\dagger}$ Corresponding author: Junichiro Ishida, Institute of Social and Economic Research, Osaka University, 6-1 Mihogaoka, Ibaraki, Osaka 567-0047, Japan. E-mail: jishida@iser.osaka-u.ac.jp

${ }^{\ddagger}$ Toshihiro Matsumura, Institute of Social Science, University of Tokyo, 7-3-1, Hongo, Bunkyo, Tokyo, 113-0033, Japan. E-mail: matsumur@iss.u-tokyo.ac.jp

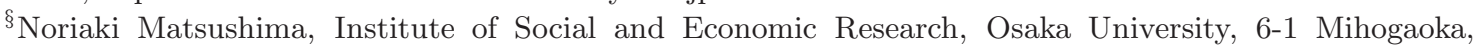
Ibaraki, Osaka 567-0047, Japan. E-mail: nmatsush@iser.osaka-u.ac.jp 


\section{Introduction}

We investigate strategic R\&D investment competition in an asymmetric Cournot model. ${ }^{1}$ The basic setup is deceptively simple and standard except for one twist: there are two types of firms which differ in terms of the initial marginal cost of production. For expositional clarity, we refer to firms with the lower marginal cost as low-cost firms and those with the higher marginal cost as high-cost firms. Before engaging in Cournot competition, each firm has a chance to reduce its marginal cost through $R \& D$ investments. Within this setup, we explore how the intensity of market competition, measured by an increase in the number of (high-cost) firms, affects each firm's incentive for R\&D investments as well as its resulting equilibrium profit.

The present setup yields several new results, pointing to the potential importance of the initial cost asymmetry in strategic R\&D competition. First, an increase in the number of high-cost firms can stimulate R\&D by the low-cost firms while it always reduces R\&D by the high-cost firms: as a result, accelerated competition enlarges the ex post efficiency dispersion (the difference in the marginal costs after the investment stage) between low-cost and highcost firms. Second, the ex post efficiency dispersion caused by R\&D competition can be large enough to compensate for the loss that arises from more intense market competition: the low-cost firms' profits can indeed increase with the number of high-cost firms. These results are in stark contrast to the standard setup where an increase in the number of firms typically reduces the amount of $R \& D$ investments, not to mention the equilibrium profits. Third, an increase in the number of firms can increase the Herfindal Index (HHI) because of the widening efficiency dispersion, although it can be welfare-improving due to the scale economies of R\&D investments. Finally, accelerated competition has a non-monotonic impact on the industry-wide rate of innovation if the ex ante efficiency dispersion (the difference in the marginal costs before the investment stage) is in some intermediate range.

\footnotetext{
${ }^{1}$ The standard model of strategic R\&D is formulated by Brander and Spencer (1983), and the literature dealing with strategic R\&D competition is now fairly abundant (Spence (1984), d'Aspremont and Jacquemin (1988), Suzumura (1992), Lahiri and Ono (1999), and Kitahara and Matsumura (2006)). The last two papers also focus on initial cost difference among firms but dos not investigate the relationship between market competition and R\&D.
} 
The key to our argument is the link between the ex ante efficiency dispersion among competing firms and the strategic incentive for $R \& D$ investments. ${ }^{2}$ The investment to reduce its own marginal cost works as a commitment to expand its production, which typically crowds out the other firms' output by some margin. This strategic gain is actually increasing in the number of competitors, as a unit decrease in the marginal cost can affect more firms when more of them are around. When this gain is sufficiently large, an increase in the number of competitors can actually induce some firms to invest more, consequently making them more efficient. As we will see, this could indeed happen for the low-cost firms, but never for the high-cost firms, implying that more intense market competition tends to further widen the ex post efficiency dispersion. As the market becomes more competitive, each highcost firm becomes less motivated and less efficient, consequently leaving more rents to be exploited by the low-cost firms. This gives competitive edges to the low-cost firms and, when this effect is strong enough to compensate for the loss that arises from more intense market competition, their profits rise with more high-cost competitors around.

Several recent studies have raised instances where an increase in the number of firms may actually increase firm profit. Mukherjee and Zhao (2009) consider an asymmetric Stackelberg setting where there are two incumbent firms (leader) with different marginal costs and a potential entrant (follower) with a higher marginal cost. They then show that the existence of the inefficient follower can increase the profit of the more efficient leader. The driving force of this paper is clearly different from ours as it stems from the fact that firms move sequentially. Coughlan and Soberman (2005), Chen and Riordan (2007), and Ishibashi and Matsushima (2009) also obtain similar results in simultaneous-move varieties. ${ }^{3}$ In those cases,

\footnotetext{
${ }^{2}$ In this paper, the initial productivity is defined in terms of the ex ante marginal cost (before any investment takes place), but a similar conclusion is expected to arise when it is defined in a variety of other ways. We make some comments on this in the concluding section.

${ }^{3}$ Several papers consider vertical relations between downstream and upstream firms and show that market entry can increase the incumbent downstream firms (Tyagi (1999), Mukherjee et al. (2009)). The main logic behind these results is common: entry in a downstream market causes the decrease in the wholesale price. In a bilateral oligopoly model, Naylor (2002) shows that an increase in the number of downstream firms could increase the total industry profit because more intense downstream competition shifts bargaining power in favor of the downstream firms. There is also a line of works which argue that having weak competitors might help because it keeps stronger competitors out of the market. See, for instance, Ashiya (2000) on this point.
} 
however, market entry works as a commitment device to soften market competition, so that the market actually becomes less competitive as more firms enter into it. In contrast, the low-cost firms in our model benefits more directly from intense market competition. This difference is summarized most succinctly by the following (possibly empirically testable) feature of our model: the equilibrium market price is decreasing in the number of firms in our model while it is increasing in theirs. Although we do not know a priori which scenario is more plausible, as it certainly depends on the minute details of the underlying structure, this fact may be used to discriminate between our mechanism and other existing ones when examining more specific cases.

The paper is also related to the literature which examines Cournot models with asymmetric firms. ${ }^{4}$ In particular, Salant and Shaffer (1999) show that the total industry profit increases as the marginal costs become more asymmetric while keeping the sum of the marginal costs constant. ${ }^{5}$ There is some connection with this work because the dispersion in the marginal costs widens in our model as the number of firms increases. Aside from this, however, the question we pose here is inherently different, largely on two accounts. First, our primary interest is in the impact of accelerated market competition, as captured by an increase in the number of firms, while Salant and Shaffer (1999) consider a setting where the number of firms is held constant. Second, given this difference in the scope, we then look at how each individual firm's profit, instead of the total industry profit, changes with respect to an increase in the number of firms. ${ }^{6}$ Firm asymmetries per se virtually have no bite for the question of our interest, because each individual firm's profit must decrease as the number of firms increases in typical Cournot models for any given distribution of the marginal costs, no matter how large firm asymmetries are to begin with. This fact hence suggests that a critical point of departure is our explicit focus on $R \& D$ incentives, which allows us to endogenize

\footnotetext{
${ }^{4}$ Daughety (2008) provides a succinct review on basic properties of Cournot models.

${ }^{5}$ This result owes largely to the fact that the total output depends only on the sum of the marginal costs. See Bergstrom and Varian (1985) on this point.

${ }^{6}$ It goes without saying that the profit of a firm whose marginal cost decreases must increase in the setup of Salant and Shaffer (1999). Our question about individual firm profit hence carries little significance when the number of firms is fixed. On the other hand, Salant and Shaffer (1999) has nothing to say about the case where the number of firms increases, which typically yields some impacts in Cournot models.
} 
the cost structure of an industry. Although the widening dispersion in the marginal costs works as an intermediate force along the way, this is an endogenous feature of our model (and, incidentally, one of our main contentions) which is derived in response to an increase in the number of firms.

The paper proceeds as follows. Section 2 outlines the basic environment, illustrates fundamental forces behind our setup, and derives main results. Section 3 discusses implications of the model, especially relating it to a practice known as open knowledge disclosure and what we call the Ford story. Finally, section 4 offers some concluding remarks.

\section{Competition and market outcomes in asymmetric oligopoly}

\subsection{Setup}

In order to make our point emphatically, we stick with a simple and standardized version of Cournot competition, augmented with cost-reducing R\&D investments, as much as possible. Consider an industry consisting of $n$ firms, each denoted by $i \in\{1,2, \ldots, n\} \equiv N$. We take the number of firms exogenous and fixed, except for section 2.5 where we briefly discuss the case of free entry. The model has two stages: each firm first chooses the investment level, which subsequently determines its marginal cost of production, and then engages in Cournot competition taking the realized marginal costs as given.

Let $x_{i}$ denote the investment level chosen by firm $i$. A unit increase in the investment decreases the firm's marginal cost by the same margin. The total production cost incurred by the firm is thus given by $\left(z_{i}-x_{i}\right) q_{i}$, where $q_{i}$ denotes the output level chosen by firm $i$. In this specification, $z_{i}$ signifies the ex ante marginal cost (before the investment), while $c_{i} \equiv z_{i}-x_{i}$ the ex post marginal cost (after the investment). We assume that the cost of the investment is given by by $\gamma x_{i}{ }^{2}$. The parameter $\gamma$ reflects the importance of the R\&D investment where a small $\gamma$ means that endogenous cost reduction is an important part of the production process.

In the second stage, upon observing $x_{i}$ for all $i \in N$, the firms engage in standard Cournot (quantity) competition. The inverse demand function is specified as

$$
p=1-Q
$$


where $Q=\sum_{i \in N} q_{i}$ is the total output. Each firm simultaneously chooses $q_{i}$ so as to maximize its own profit.

As can be seen, the basic setup is a text-book Cournot model with strategic R\&D investments, except that we allow $z_{i}$ to differ across firms. To illustrate our contention clearly and emphatically, for most of the analysis, we consider a case where there is one low-cost firm (firm 1) with $z_{1}=z_{L}$ and $n-1$ high-cost firms (firms 2-n) with $z_{i}=z_{H}>z_{L}$. In what follows, we examine subgame perfect equilibria of this complete-information game.

\subsection{Competition stimulates investments by the rich}

In this subsection, we go through the optimization problems faced by each firm. Since the model is standard enough, we only briefly sketch the outline of the analysis.

In the second stage, given the realized marginal costs for all $i \in N$, each firm chooses its output $q_{i}$. Each firm's problem in this stage can be written as

$$
\max _{q_{i}} \pi_{i} \equiv\left(1-\sum_{j=1}^{n} q_{j}-c_{i}\right) q_{i} .
$$

Assuming that the interior solutions exist, the equilibrium output is obtained as

$$
q_{i}=\frac{1+\sum_{j \neq i}\left(z_{j}-x_{j}\right)-n\left(z_{i}-x_{i}\right)}{n+1} .
$$

It follows from this that the optimal output is a function of the investment levels, and we write $q_{i}^{E}\left(x_{1}, x_{2}, \ldots, x_{n}\right)$, where superscript $E$ henceforth denotes the equilibrium value of any respective endogenous variable. This immediately leads us to obtain the equilibrium (gross) profit of each firm:

$$
\pi_{i}^{E}\left(x_{1}, x_{2}, \ldots, x_{n}\right)=\left(1-\sum_{j=1}^{n} q_{j}^{E}-c_{i}\right) q_{i}^{E}=\frac{\left(1+\sum_{j \neq 1}\left(z_{j}-x_{j}\right)-n\left(z_{i}-x_{i}\right)\right)^{2}}{(n+1)^{2}}
$$

which is also a function of the investment levels.

In the first stage, each firm simultaneously decides how much to invest in reducing the marginal cost. The first-period problem faced by each firm is defined as choosing $x_{i}$ to maximize the net profit $\Pi_{i}$, taking the other firms' choices as given:

$$
\max _{x_{i}} \Pi_{i}\left(x_{1}, x_{2}, \ldots, x_{n}\right) \equiv \pi_{i}^{E}\left(x_{1}, x_{2}, \ldots, x_{n}\right)-\gamma x_{i}{ }^{2}
$$


The equilibrium investment level of firm $i$ is obtained as

$$
x_{i}^{E}\left(n, \mathbf{z} ; z_{i}\right)=\frac{n\left[((n+1) \gamma-n)+(n+1) \gamma \sum_{j=1}^{n} z_{j}-\left((n+1)^{2} \gamma-n\right) z_{i}\right]}{((n+1) \gamma-n)\left((n+1)^{2} \gamma-n\right)} .
$$

Notice that the second-order condition is satisfied if and only if

$$
\frac{n^{2}}{(n+1)^{2}}-\gamma<0
$$

We assume that $\gamma \geq 1$ so that the second order condition is satisfied for any given $n$. The profit of firm $i$ is denoted by

$$
\pi_{i}\left(n, \mathbf{z} ; z_{i}\right)=\left(\gamma^{2} \frac{(n+1)^{2}}{n^{2}}-\gamma\right)\left(x_{i}^{E}\left(n, \mathbf{z} ; z_{i}\right)\right)^{2} .
$$

Before we proceed further, we need to check whether the interior solutions indeed exist, which we have thus far taken for granted. To check this, we only need to look at the high-cost firms since $q_{1}^{E}>0$ and $x_{1}^{E}>0$ if $q_{i}^{E}>0$ and $x_{i}^{E}>0, i \neq 1$. For the high-cost firms, $q_{i}^{E}>0$ for any given $n$ if and only if

$$
z_{L}>\frac{((2 \gamma-1) n+2 \gamma) z_{H}-((\gamma-1) n+\gamma)}{\gamma(n+1)} \equiv \underline{z}_{L} .
$$

Notice that this is also the necessary and sufficient condition for $x_{i}>0$ : with a quadratic cost function, a firm would invest in cost reduction if and only if it produces a positive amount. We restrict our attention to the case where $z_{L}>\underline{z}_{L}$ so that the high-cost firms have some role to play.

We are interested in how an increase in $n$, triggered by a new entry of a high-cost firm, affects market outcomes in this asymmetric environment. To this end, we first examine the relationship between market entry and the incentive for cost reduction.

Proposition 1 For any $n>1$ and $\gamma \geq 1$, (i) there exists some nonempty interval $Z^{x} \equiv$ $\left(\underline{z}_{L}, z_{L}^{x}\right)$ such that $x_{1}^{E}$ is increasing in $n$ if and only if $z_{L} \in Z^{x}$; (ii) $x_{i}^{E}, i \neq 1$, is decreasing in $n$.

The proposition makes two claims. The first claim is the more illuminating part, which says that the low-cost firm's R\&D investment can be increasing in $n$. The key factor turns 
out to be the relative location of $z_{H}$ and $z_{L}$, i.e., the dispersion in the ex ante marginal costs between the low-cost and the high-cost firms. The low-cost firm is induced to make more investment as $n$ increases when the high-cost firms are ex ante sufficiently (but not too) inefficient relative to the low-cost firm. As the market become more competitive, therefore, the dispersion in the ex post marginal costs may become even larger. Moreover, it says that $Z^{x}$ is generally nonempty, meaning that we can always find some $z_{L}$ such that $\partial x_{1}^{E} / \partial n>0$. These results are in stark contrast to the standard setup where an increase in $n$ typically reduces the investment level because it implies smaller rents for innovating firms.

More intense competition is more likely to induce the low-cost firm to invest more when the upperbound $z_{L}^{x}$ is larger. Not surprisingly, this is the case when $\gamma$ is relatively small, i.e., when R\&D investments are sufficiently important in the production process. The next proposition is a formal representation of this fact.

Proposition 2 For any $n>1$ and $\gamma \geq 1, \partial z_{L}^{x} / \partial \gamma<0$.

The range for which the low-cost firm's investment increases with $n$ can be best seen graphically. Figure 1 illustrates the range for two different values of $\gamma$. These examples indicate that the low-cost firm's investment increases with $n$ for a wide range of parameter values.

[Figure 1 here]

\subsection{Competition makes the rich get richer}

When $z_{L} \in Z^{x}$, more intense competition makes the low-cost firm even more superior in the sense that the dispersion in the ex post marginal costs becomes wider. When this effect is strong enough to compensate the loss from more intense market competition, the low-cost firm's profit may actually increase as more high-cost firms enter the market. This can indeed happen, as the next proposition indicates.

Proposition 3 For any $n>1$ and $\gamma \geq 1$, (i) there exists some nonempty interval $Z^{P} \equiv$ $\left(\underline{z}_{L}, z_{L}^{P}\right)$ such that $\Pi_{1}^{E}$ is increasing in $n$ if and only if $z_{L} \in Z^{P}$; (ii) $\Pi_{i}^{E}, i \neq 1$, is decreasing in $n$. 
Proposition 3 is the main result of the paper, which basically runs parallel to Proposition 1, making two claims of similar nature. In particular, it again shows that $Z^{P}$ is nonempty for any given $n>1$ and $\gamma \geq 1$, and hence we can always find $z_{L}$ such that $\partial \Pi_{1}^{E} / \partial n>0$. As the market becomes more competitive, the low-cost firm invests more (if $z_{L} \in Z^{x}$ ) and the high-cost firms invest less. As a consequence, the dispersion in the marginal costs gets even larger at the ex post stage when the firms engage in Cournot competition. The low-cost firm can benefit from this, even though ex post market competition becomes severer as $n$ increases.

Competition induces the low-cost firm to invest more when $\gamma$ is relatively small, and this same logic apparently carries over to the low-cost firm's profit. The next proposition is a sequel to Proposition 2, showing that the dispersion in the ex ante marginal costs needs to be small in environments where R\&D investments are sufficiently important.

Proposition 4 For any $n>1$ and $\gamma \geq 1, \partial z_{L}^{P} / \partial \gamma<0$.

Figure 2 illustrates the range of $z_{L}$ for which the low-cost firm's profit is increasing in $n$, again for two different values of $\gamma$. Naturally, the range for which the low-cost firm's profit increases is narrower than that for which its investment increases. In fact, as can be expected, the low-cost firm's profit increases with $n$ only if its investment increases with $n$, i.e., the former is a necessary condition of the latter.

Proposition 5 For any $\gamma \geq 1$ and $n>1, Z^{P} \subset Z^{x}$.

[Figure 2 here]

Remark: We have thus far restricted our attention to a specific distribution of the ex ante marginal costs, i.e., one low-cost firms and $n-1$ identical high-cost firms. We must note that this assumption is not essential to derive our main observation, as it holds for other "nearby" distributions. In essence, whether a new market entry increases any given firm's profit increases depends on three factors: the firm's own ex ante marginal cost, the average ex ante marginal cost among all the other incumbent firms, and the new entrant's ex ante marginal cost. Now suppose that there are initially $n$ incumbent firms whose ex ante 
marginal costs are given by $\mathbf{z}=\left(z_{L}, z_{2}, \ldots, z_{n}\right)$ : here, we allow for some heterogeneity among $z_{i}, i=2,3, \ldots, n$. We then add a new firm, firm $n+1$, to the market with $z_{n+1}=z_{e}$ and see how it affects the low-cost firm's profit. Formally, we investigate the condition under which this entry benefits the low-cost firm, i.e.,

$$
\pi_{1}\left(n, \mathbf{z} ; z_{L}\right)<\pi_{1}\left(n+1, \mathbf{z}^{\prime} ; z_{L}\right)
$$

where $\pi_{1}$ is the equilibrium net profit as given in (6) and $\mathbf{z}^{\prime}=\left(\mathbf{z}, z_{e}\right)$. Figure 3 illustrates this condition. ${ }^{7}$ As the figure indicates, our main contention holds even when there is some heterogeneity among the other incumbent firms as long as the entrant is sufficiently less efficient in terms of the ex ante marginal cost.

[Figure 3 here]

\subsection{What happens at the aggregate level?}

Several recent studies have raised instances where incumbents benefit from a new market entry. In those previous cases, however, the equilibrium price actually rises with a new entrant coming into the market: market competition becomes less severe despite the fact that there are now more firms in the market. What is common among those previous studies is therefore that they find a channel through which a market entry somehow makes the market less competitive. In Ishibashi and Matsushima (2009), for instance, a new entry into the low-end market works as a commitment device for the incumbents not to supply to that market (hence not to lower the price to accommodate low-end consumers). This is actually profit-enhancing for the incumbents as they can focus on the high-end market, allowing them to charge a higher price to high-end consumers.

In contrast, our model works in a totally different way. The difference is succinctly summarized by a distinguishing, and empirically testable, feature of our model: the equilibrium price is indeed decreasing in $n$ so that the market becomes truly more competitive as $n$ increases. In our model, there is nothing unusual about the impact that an increase in $n$ has

\footnotetext{
${ }^{7}$ When the entrant is too efficient, some incumbent firms may exit from the market; when the incumbent firms are on average too efficient, the entrant cannot make any positive profit. The two intersecting lines in the figure represent these conditions. The segmented line is the condition under which the entrant with $z_{e}$ increases the low-cost firm's profit.
} 
on the equilibrium market price. ${ }^{8}$ To see this, the equilibrium price is computed as

$$
p^{E}=\frac{(n+1)\left(1+(n-1) z_{H}+z_{L}\right) \gamma-n}{(n+1)^{2} \gamma-n},
$$

which straightforwardly leads to the next result.

Proposition 6 For any $n>1$ and $\gamma \geq 1, p^{E}$ is decreasing in $n$.

That the equilibrium price is decreasing in $n$ necessarily means that the total quantity supplied is increasing. This naturally raises a question about the composition of the total output (or the market share). To see this, let $Q_{-1}^{E}$ denote the total quantity supplied by all of the high-cost firms, which is given by

$$
Q_{-1}^{E}=\frac{\gamma\left(n^{2}-1\right)\left[\left(1-2 z_{H}+z_{L}\right)(n+1) \gamma-\left(1-z_{H}\right) n\right]}{\left((n+1)^{2} \gamma-n\right)((n+1) \gamma-n)} .
$$

Surprisingly, the total output supplied by the high-cost firms may decrease with $n$.

Proposition 7 (i) For any $n>1$ and $\gamma \geq 1$, (i) there exists some nonempty interval $Z^{Q} \equiv\left(\underline{z}_{L}, z_{L}^{Q}\right)$ such that $Q_{-1}^{E}$ is decreasing in $n$ if $z_{1} \in Z^{Q}$; (ii) $Z^{P} \subset Z^{Q} \subset Z^{x}$.

It directly follows from Proposition 6 that the total quantity supplied is increasing in $n$, as in standard Cournot models. This implies that if $Q_{-1}^{E}$ decreases with $n$, then $q_{1}^{E}$ must increase - yet another unusual property. This also implies that $z_{1} \in Z^{Q}$ is a sufficient condition for the low-cost firm's market share to increase with $n$.

Remark: The results also yield a welfare implication of some interest. An increase in the number of high-cost firms can actually increase the Herfindal Index (HHI) because it enlarges the asymmetry among firms (see Proposition 1). Nevertheless, it can be welfare-improving because the scale economies of R\&D investments can be substantial enough. ${ }^{9}$ Moreover, it

\footnotetext{
${ }^{8}$ Of course, our intention is not to exclude those existing views on this ground because there can be many channels through which an incumbent benefits from a market entry. Which view is more plausible depends certainly on the underlying structure and is purely an empirical matter left for future research. We argue, however, that this fact provides a nice discriminating factor when one examines what forces are more likely to be at work in each specific case.

${ }^{9}$ Although it is straightforward to see that an entry improves social welfare in symmetric Cournot models, this does not necessarily hold when the firms are asymmetric as in this case. See Lahiri and Ono (1988) for this point.
} 
is also consumer-benefiting (see Proposition 6). All in all, these facts suggest that HHI may be an inappropriate welfare index under certain conditions, as has been well recognized by now. ${ }^{10}$ The current setup provides yet another example of this assertion.

Finally, we briefly discuss the impact of market competition on the industry-wide rate of innovation. The question we ask here is whether market competition spurs or inhibits innovations in our setup. To this end, suppose that we measure the industry-wide rate of innovation by the (effective) total investment $M$ :

$$
M \equiv \gamma x_{1}^{2}+\gamma \sum_{i \neq 1} x_{i}^{2}
$$

Figure 4 provides some numerical examples of the relationship between $M$ and $n$. As the figure indicates, almost anything goes in our setup, and no clear prediction can hence be made from this. First, if the dispersion in the ex ante marginal costs is small and $z_{L}>z_{L}^{x}$, the low-cost firm's investment decreases with $n$, and the total investment is more likely to decrease (see two examples on the left-hand side of Figure 4). On the contrary, when the dispersion is large, the low-cost firm invests more as $n$ increases, even to the extent that it more than offset a decrease in the total investment of the high-cost firms. As a consequence, the total investment is more likely to be increasing in $n$ (see two examples on the right-hand side). If the dispersion is in some intermediate range, the total investment is non-monotone with respect to $n$ (see examples at the middle). The last case where the dispersion falls into some intermediate range is perhaps most interesting, as recent evidence seems to suggest that the relationship between market competition and innovation is inverted U-shape, e.g., Aghion and Griffith (2005). ${ }^{11}$

[Figure 4 here]

The literature examining the relationship between market competition and innovation is very large and diverse, as it is certainly an old issue which have attracted attention of many

\footnotetext{
10 This has been discussed in many contexts. See, for instance, Daughety (1990), Etro (2007) and Davidson and Mukherjee (2007).

${ }^{11}$ For theoretical analyses on the relationship between competition and innovation, see, e.g., Vives (2008) and Zhou (2009).
} 
economists, at the very least from the days of Schumpeter, and many models have been proposed to account for observed patterns of the relationship between market competition and innovation, e.g., Aghion et al. (2005). We thus do not intend to make too much out of this, because we only analyze a very specific industry structure. If there is anything we can insist on this, though, at least this much is certain: the distribution of (initial) productivity matters, even in a simple Cournot framework like ours. This is an insight which, in our view, has not received enough attention, and it is of some interest to approach this issue from this perspective, both theoretically and empirically.

\subsection{The case of free entry}

While our analysis takes the number of (high-cost) firms as exogenous, we can easily extend our model to incorporate free entry by high-cost firms. Suppose that firms enter the market at their own discretion by incurring some fixed entry cost. More precisely, consider the following three-stage game: 1 . potential followers decide whether to enter the market; 2 . each firm invests in R\&D; and 3. each firm engages in Cournot competition. Let $F$ denote the fixed cost that a new entrant must incur, which effectively determines the equilibrium number of firms. One can then easily see that a decrease in the entry cost, which typically intensifies market competition, can raise the low-cost firm's profit in the current setting. ${ }^{12}$ This fact yields a critical insight, as dominant firms in an industry may have an incentive to lower, rather than raise, the entry barrier faced by which minor competitors, e.g., via partial disclosure of critical know-how. We will explore more on this point in the next section.

\section{Open knowledge disclosure: the Ford story}

In the previous sections, we have analyzed a simple Cournot model with strategic R\&D investments when the firms are inherently asymmetric. The most important message here is

\footnotetext{
${ }^{12}$ On the other hand, the situation would become more complicated, and perhaps more intriguing, with a slight change in the timing structure. For instance, suppose that there is only one low-cost firm to begin with and the low-cost firm has an opportunity to invest in R\&D prior to the entry of potential followers, as considered in Etro $(2004,2006,2008)$. This context require a whole new analysis, as a leader now has an incentive to make aggressive investments strategically to deter the entry of followers. For the discussion of R\&D competition in Stackelberg settings, see also Ino and Kawamori (2009).
} 
that firms with more advanced technologies may benefit from having more minor competitors. We argue that an implication that this leads to is rather far-reaching, because those dominant firms actually have an incentive to help, rather than harm, minor competitors so that they can remain just sufficiently competitive to stay in the market. In this section, we focus on this implication of the model by relating it to a practice known as open knowledge disclosure and especially the case of Ford back at the turn of the 20th century.

To discuss this issue, let us start with the following question: why are some firms more productive than others? A relatively straightforward way to answer this question is that if there is any sure way to gain market power, it is to make new innovations over the existing ways of production and commercialization. In fact, innovations, in a broad sense, are the typical and sometimes the only source of competitive edges that a firm can gain over its existing or potential competitors. For instance, a firm may drive competitors out of the market if it can attain a level of efficiency that no one can catch up to. New ideas are also indispensable to invent a unique, differentiated, product that cannot easily be imitated. The problem, as it has been clearly recognized, is that although innovative ideas are surely hard to come by, they are very easy to copy once they are created: in fact, most ideas can be copied at almost no cost. It is hence critical for innovating firms to establish and protect their innovative ideas, provided that they can benefit from being in less competitive environments.

In reality, though, firms do not seem overly concerned about keeping "secrets" to themselves - at least not always. For instance, it is often suggested that a large fraction of patentable innovations are not patented (Mansfield, 1986). ${ }^{13}$ Firms are not simply reckless with their secrets; they often go beyond just that as they intentionally and freely disclose what appears to be critical knowledge, even to their direct competitors. Informal know-how trading between competitors is very active, often though informal networks of process engineers (von Hippel, 1988). Employees frequently give technical information to colleagues in other firms, including direct competitors (Schrader, 1991). All of these seem to suggest that firms do not protect their innovations as carefully as the theory predicts.

Of course, some fraction of know-how trading occurs in a closed setting - the practice

\footnotetext{
${ }^{13}$ A typical view on this is that patents are not always the best way to protect their ideas. This might be due to the limited power of Intellectual Property (IP) rights. Anton and Yao (2004) focus on this aspect.
} 
often referred to as closed knowledge disclosure. ${ }^{14}$ In this case, some reciprocal agreements, either explicitly or implicitly, can in principle be made between the giver and the recipients, barring many difficulties associated with trading ideas. ${ }^{15}$ In many instances, though, firms not just freely but also publicly give away critical knowledge through open channels such as publications in scientific journals, presentation in conferences or more informal communication - a practice often referred to as open knowledge disclosure. ${ }^{16}$ This practice is highly puzzling because, when a firm makes its critical knowledge publicly accessible, it inevitably loses some, if not all, control over the diffusion of the know-how. Once the know-how becomes publicly available, it is virtually impossible for the disclosing firm to take it back or to make any profit from it. No future exchange of favors can be expected either because it is nearly impossible to identify the beneficiaries of the know-how when it is disclosed via open channels.

One story stands out in this respect. At the beginning of the 20th century, Ford was the low-cost automobile producer which had attained an unprecedented level of efficiency with radically new technologies. The pace of growth was astonishing, especially considering the fact that the entire industry had also been growing at a rapid pace. Ford's share of all automobile production grew from $9.4 \%$ in 1908 to $48 \%$ in $1914 .{ }^{17}$ In its main filed of competition, i.e., the cheap car filed, Ford's share was $96 \%$, practically making it a monopolist. The figures suggest Ford's incredible presence in the industry, given that the industry was not as concentrated as it is today. ${ }^{18}$ There were certainly many factors that had contributed to

\footnotetext{
14 There is a scope for know-how trading especially if the industry profit increases with the number of
} firms. In this case, the concerned parties could reach an agreement if they can somehow manage to find a way to appropriately divide the surplus (perhaps through some explicit contracts).

15 Trading an idea is difficult especially when its quality is uncertain: a recipient must see the idea to evaluate the quality but, once the idea is observed, there is no reason to buy it. Partial disclosure may be optimal in a situation like this. See Anton and Yao (2004) for this.

16 A seminal work on open knowledge disclosure is Allen (1983) who argues that many new production technologies have been developed by a process called "collective invention." See Pénin (2007) for further evidence on open knowledge disclosure. Creane and Konishi (2009) argue that technology transfers through joint production can be beneficial for the technologically advanced firm because that may deter entry or predate on other rival firms.

17 All figures are taken from Nevins (1954).

18 At the time, the number of manufacturers exceeded well above one hundred. 
Ford's success, but the main source of its competitive edges was undoubtedly its production efficiency made possible by several innovations and inventions such as the moving assembly line system and Henry Ford's scientific management (or so-called "Fordism"): in 1914, Ford, only with 13,000 employees, manufactured 260,720 while all of the other companies, with 66,350 employees combined, manufactured mere 286,770. There was virtually no competition; Ford was simply too good. Surprisingly, though, Ford had no intention of "hiding its secrets." Nevins (1954, p.508) notes:

Engineers came from all over America and Europe to study this achievement in efficiently standardized and specialized production. Nothing was concealed. Indeed, Henry Ford and his associates this year cooperated with the editors of Engineering in laying before the world, in the technically detailed and richly illustrated pages of Arnold and Faurote's Ford Methods and the Ford Shops, ...

It is hard to believe that Ford expected something in return from those fringe competitors which seemed to have nothing worthwhile to offer at the time. Why did Ford give away its critical knowledge so generously? Our model provides a partial answer to this and, more broadly, a sensible reason for open knowledge disclosure: there is a channel through which the innovating firm can benefit from disseminating its innovative ideas publicly. The Ford story fits our description particularly well for two reasons: (i) endogenous cost reduction a driving force of our model - is evidently an important factor in the automobile industry; (ii) Ford possessed apparently superior technologies and cost advantages. In a situation like this, market competition tends to make a low-cost firm even more efficient, and hence eliminating high-cost competitors was not necessarily in its best interest. When there are more high-cost competitors, competition among them becomes severer and that discourages them. High-cost competitors make less investment and, consequently, become less efficient, which actually works for the low-cost firm. According to this logic, Ford had every reason to help, rather than harm, high-cost competitors so that they can remain (just sufficiently) competitive in the market. 


\section{Conclusion}

In this paper, we revisit a fundamental question regarding the nature of market competition: does intense market competition always make firms worse off? We identify a situation under which the widely accepted view that intense market competition decreases firm profit fails to ascertain itself. In a market consisting of inherently asymmetric firms, firms with advanced technologies can in fact benefit from having more (high-cost) competitors when endogenous cost reduction is sufficiently important. Our model also implies that in some cases, there is a reason for low-cost firms to help, rather than harm, high-cost competitors, just for their own sake (even without any spillover or network effects). This implication of the model provides a plausible explanation for open knowledge disclosure and especially Ford's strategy at the beginning of the 20th century.

It is our view that the present analysis provides only a first step to better understand the nature of market competition in asymmetric oligopoly, and hence that there are several avenues to extend the current analysis. First, our results should hold even when the firms are ex ante asymmetric in more broad senses. More specifically, although the initial efficiency is defined only in terms of the ex ante marginal cost of production, a similar conclusion holds when it is defined, for instance, in terms of the efficiency of cost reduction, (measured by $\gamma$ in

the model). Second, for most of the analysis, we restrict our attention to a particular industry structure - one low-cost firm and $n-1$ equally inefficient high-cost firms - to make our points in a relatively clear manner, but the model's implications are certainly not restricted to this structure. Our main contention is rather that the distribution of initial productivity matters, for the incentive for $R \& D$ investments and the resulting equilibrium profits. We believe that this is an important insight especially when we examine the relationship between market competition and innovation, and it is of some interest to pursue this aspect, both theoretically and empirically, in future. 


\section{Appendix: proofs}

Proof of Proposition 1 (i) From (4) we have

$$
\begin{aligned}
\frac{\partial x_{1}^{E}}{\partial n}= & \frac{\gamma\left[n^{2}\left(n^{2}+1\right)-3 n^{2}(n+1)^{2} \gamma+(n+1)^{3}(3 n-1) \gamma^{2}\right] z_{H}}{((n+1) \gamma-n)^{2}\left((n+1)^{2} \gamma-n\right)^{2}} \\
& -\frac{\gamma\left[\left(n^{2}-1\right)((n+1) \gamma-n)^{2}+n\left(2 n-(n+1)^{2}(n+2) \gamma+2(n+1)^{3} \gamma^{2}\right) z_{L}\right]}{((n+1) \gamma-n)^{2}\left((n+1)^{2} \gamma-n\right)^{2}}
\end{aligned}
$$

which is positive if and only if

$$
\begin{aligned}
& z_{L}<\frac{\left(n^{2}-1\right)((n+1) \gamma-n)^{2}}{n\left(2 n-(n+2)(n+1)^{2} \gamma+2(n+1)^{3} \gamma^{2}\right)} \\
& +\frac{\left[n^{2}\left(1+n^{2}\right)-3 n^{2}(n+1)^{2} \gamma+(3 n-1)(n+1)^{3} \gamma^{2}\right] z_{H}}{n\left(2 n-(n+2)(n+1)^{2} \gamma+2(n+1)^{3} \gamma^{2}\right)} \equiv z_{L}^{x} .
\end{aligned}
$$

For the nonemptiness, see the Proof of Proposition 5.

(ii) From (4) we have

$$
\begin{array}{r}
\frac{\partial x_{i}^{E}}{\partial n}=-\gamma\left[\frac{\left[(n-1)(n+1)^{3} \gamma^{2}-n^{2}(n+1)^{2} \gamma+n^{2}\right] z_{L}+\left(n^{2}-1\right)((n+1) \gamma-n)^{2}}{((n+1) \gamma-n)^{2}\left((n+1)^{2} \gamma-n\right)^{2}}\right. \\
\left.-\frac{\left[2(n-1)(n+1)^{3} \gamma^{2}-n(n+1)^{2}(3 n-2) \gamma+n^{4}\right] z_{H}}{((n+1) \gamma-n)^{2}\left((n+1)^{2} \gamma-n\right)^{2}}\right], i \neq 1,
\end{array}
$$

which is maximized at $z_{L}=\underline{z}_{L}$ (because $\partial x_{i}^{E} / \partial n, i \neq 1$, is strictly decreasing in $z_{L}$ ). Evaluating the partial derivative at this value, we have

$$
\left.\frac{\partial x_{i}^{E}}{\partial n}\right|_{z_{L}=\underline{z}_{L}}=-\frac{n\left(1-z_{H}\right)}{(n+1)((n+1) \gamma-n)\left((n+1)^{2} \gamma-n\right)}<0, \quad i \neq 1 .
$$

Therefore, under the maintained assumptions, $x_{i}^{E}, i \neq 1$, is strictly decreasing in $n$ as long as $z_{L}>\underline{z}_{L}$ and $x_{i}^{E}>0$.

Q.E.D.

Proof of Proposition 2 Differentiating $z_{L}^{x}$ with respect to $\gamma$, we have

$$
\frac{\partial z_{L}^{x}}{\partial \gamma}=\frac{-\left(1-z_{H}\right)(n-1)(n+1)^{2}((\gamma-1) n+\gamma)\left((n+1)^{2}(3 n-2) \gamma-n\left(n^{2}+3 n-2\right)\right)}{n\left(2 n-(n+2)(n+1)^{2} \gamma+2(n+1)^{3} \gamma^{2}\right)^{2}} .
$$

Note that $(n+1)^{2}(3 n-2) \gamma-n\left(n^{2}+3 n-2\right)>0$ for any $\gamma>1$ because, when $\gamma=1$,

$$
(n+1)^{2}(3 n-2) \gamma-n\left(n^{2}+3 n-2\right)=2 n^{3}+n^{2}+n-2>0 .
$$


This means that the numerator of $\partial z_{L}^{x} / \partial \gamma$ is always negative.

Q.E.D.

Proof of Proposition 3 (i) Given the equilibrium investment levels, we can obtain the net profits as follows:

$$
\begin{gathered}
\Pi_{1}^{E}=\frac{\gamma\left((n+1)^{2} \gamma-n^{2}\right)\left((n+1) \gamma-n+\left(n^{2}-1\right) \gamma z_{H}-n((n+1) \gamma-1) z_{L}\right)^{2}}{((n+1) \gamma-n)^{2}\left((n+1)^{2} \gamma-n\right)^{2}}, \\
\Pi_{i}^{E}=\frac{\gamma\left((n+1)^{2} \gamma-n^{2}\right)\left((n+1) \gamma-n+(n+1) \gamma z_{L}-(2(n+1) \gamma-n) z_{H}\right)^{2}}{((n+1) \gamma-n)^{2}\left((n+1)^{2} \gamma-n\right)^{2}}, i \neq 1 .
\end{gathered}
$$

From (18), we have

$$
\begin{gathered}
\frac{\partial \Pi_{1}^{E}}{\partial n}=2 \gamma^{2}\left((n+1) \gamma-n+\left(n^{2}-1\right) \gamma z_{H}-n((n+1) \gamma-1) z_{L}\right) \times \\
\left\{\frac{(n+1)((n+1) \gamma-n)^{2}\left((n+1)^{2} \gamma-\left(n^{2}-n+1\right)\right)}{((n+1) \gamma-n)^{3}\left((n+1)^{2} \gamma-n\right)^{3}}\right. \\
-\frac{\left[n^{2}(1-n)+n^{3}(n+1)^{2} \gamma-(n+1)^{3}\left(2 n^{2}+1\right) \gamma^{2}+(n+1)^{5} \gamma^{3}\right] z_{L}}{((n+1) \gamma-n)^{3}\left((n+1)^{2} \gamma-n\right)^{3}} \\
\left.-\frac{\left[n^{3}\left(1+n^{2}\right)-n(n+1)^{2}\left(4 n^{2}-n+2\right) \gamma+(n+1)^{3}\left(5 n^{2}+n+2\right) \gamma^{2}-2(n+1)^{5} \gamma^{3}\right] z_{H}}{((n+1) \gamma-n)^{3}\left((n+1)^{2} \gamma-n\right)^{3}}\right\},
\end{gathered}
$$

which is positive if and only if

$$
\begin{aligned}
z_{L}<-\frac{(n+1)((n+1) \gamma-n)^{2}\left((n+1)^{2} \gamma-\left(n^{2}-n+1\right)\right)}{\left[n^{2}(1-n)+n^{3}(n+1)^{2} \gamma-(n+1)^{3}\left(2 n^{2}+1\right) \gamma^{2}+(n+1)^{5} \gamma^{3}\right]} \\
+\left[\frac{\left[-n^{3}\left(n^{2}+1\right)+n(n+1)^{2}\left(4 n^{2}-n+2\right) \gamma\right] z_{H}}{\left[n^{2}(1-n)+n^{3}(n+1)^{2} \gamma-(n+1)^{3}\left(2 n^{2}+1\right) \gamma^{2}+(n+1)^{5} \gamma^{3}\right]}\right. \\
\left.+\frac{\left[-(n+1)^{3}\left(5 n^{2}+n+2\right) \gamma^{2}+2(n+1)^{5} \gamma^{3}\right] z_{H}}{\left[n^{2}(1-n)+n^{3}(n+1)^{2} \gamma-(n+1)^{3}\left(2 n^{2}+1\right) \gamma^{2}+(n+1)^{5} \gamma^{3}\right]}\right] \equiv z_{L}^{P}
\end{aligned}
$$

For the nonemptiness, see the Proof of Proposition 5.

(ii) From (19) we have

$$
\frac{\partial \Pi_{i}^{E}}{\partial n}=-2 \gamma^{2}\left(\gamma(n+1) z_{L}+((\gamma-1) n+\gamma)-((2 \gamma-1) n+2 \gamma) z_{H}\right) K(n, \gamma), i \neq 1,
$$

where

$$
\begin{gathered}
K(n, \gamma)=\frac{\left[(n+1)^{5} \gamma^{3}-(n+1)^{3}\left(2 n^{2}+n+2\right) \gamma^{2}+n(n+1)^{2}\left(n^{2}+2\right) \gamma-n^{3}\right] z_{L}}{((n+1) \gamma-n)^{3}\left((n+1)^{2} \gamma-n\right)^{3}} \\
-\frac{\left[2(n+1)^{5} \gamma^{3}-(n+1)^{3}\left(5 n^{2}+2 n+3\right) \gamma^{2}+n(n+1)^{2}\left(4 n^{2}-n+4\right) \gamma-n^{2}\left(n^{3}+n+1\right)\right] z_{H}}{((n+1) \gamma-n)^{3}\left((n+1)^{2} \gamma-n\right)^{3}} \\
+\frac{(n+1)((n+1) \gamma-n)^{2}\left((n+1)^{2} \gamma-\left(n^{2}-n+1\right)\right)}{((n+1) \gamma-n)^{3}\left((n+1)^{2} \gamma-n\right)^{3}}
\end{gathered}
$$


For any $z_{L} \geq \underline{z}_{L},\left(\gamma(n+1) z_{L}+((\gamma-1) n+\gamma)-((2 \gamma-1) n+2 \gamma) z_{H}\right)$ is nonnegative. We can thus prove the proposition if $K(n, \gamma)>0$. Note that since $K(n, \gamma)$ is increasing in $z_{L}$, it suffices to show this at $z_{L}=\underline{z}_{L}$ :

$$
\frac{\left(1-z_{H}\right)\left((\gamma-1) n^{2}+2 \gamma n+\gamma\right)}{(n+1) \gamma((n+1) \gamma-n)^{2}\left((n+1)^{2} \gamma-n\right)^{2}}>0
$$

This shows that for any $n, \Pi_{i}^{E}, i \neq 1$, is decreasing in $n$.

Q.E.D.

Proof of Proposition 4 Differentiating $z_{L}^{P}$ with respect to $\gamma$, we have

$$
\frac{\partial z_{L}^{P}}{\partial \gamma}=J(n, \gamma) \frac{\left(1-z_{H}\right) n(n+1)^{2}((\gamma-1) n+\gamma)}{\left[n^{2}(1-n)+n^{3}(n+1)^{2} \gamma-(n+1)^{3}\left(2 n^{2}+1\right) \gamma^{2}+(n+1)^{5} \gamma^{3}\right]^{2}},
$$

where

$$
\begin{aligned}
J(n, \gamma) \equiv & n\left(n^{5}-3 n^{3}+5 n^{2}-3 n+2\right)-(n+1)^{2}\left(3 n^{4}-3 n^{3}+2 n^{2}+n+2\right) \gamma \\
& +(n+1)^{4}\left(3 n^{2}-3 n+4\right) \gamma^{2}-(n+1)^{6} \gamma^{3} .
\end{aligned}
$$

Note that $\partial z_{L}^{P} / \partial \gamma<0$ if and only if $J(n, \gamma)<0$. To show this, we first obtain

$$
\begin{aligned}
\frac{\partial J(n, \gamma)}{\partial \gamma}= & -(n+1)^{2}\left(3 n^{4}-3 n^{3}+2 n^{2}+n+2\right) \\
& +2(n+1)^{4}\left(3 n^{2}-3 n+4\right) \gamma-3(n+1)^{6} \gamma^{2}, \\
\frac{\partial^{2} J(n, \gamma)}{\partial \gamma^{2}}= & 2(n+1)^{4}\left(3 n^{2}-3 n+4\right)-6(n+1)^{6} \gamma, \\
\frac{\partial^{3} J(n, \gamma)}{\partial \gamma^{3}}= & -6(n+1)^{6}<0 .
\end{aligned}
$$

Substituting $\gamma=1$ into $J(n, \gamma), \partial J(n, \gamma) / \partial \gamma$, and $\partial^{2} J(n, \gamma) / \partial \gamma^{2}$ yield

$$
\begin{aligned}
J(n, 1) & =-\left(7 n^{4}+7 n^{3}+9 n^{2}-4 n-1\right)<0 \\
\left.\frac{\partial J(n, \gamma)}{\partial \gamma}\right|_{\gamma=1} & =-3(n+1)^{2}\left(n^{3}+6 n^{2}+n-1\right)<0, \\
\left.\frac{\partial^{2} J(n, \gamma)}{\partial \gamma^{2}}\right|_{\gamma=1} & =-2(n+1)^{4}(9 n-1)<0,
\end{aligned}
$$

which assures that $J(n, \gamma)$ is always negative.

Q.E.D. 
Proof of Proposition 5 With some algebra we obtain

$$
\begin{aligned}
z_{L}^{x}-z_{L}^{P}= & \frac{\left(1-z_{H}\right)(n+1)((n+1) \gamma-n)^{2}\left((n+1)^{2} \gamma-n\right)^{2}\left((n+1)^{2} \gamma-\left(n^{2}+1\right)\right)}{n\left[2 n-(n+2)(n+1)^{2} \gamma+2(n+1)^{3} \gamma^{2}\right] \Gamma}>0, \\
z_{L}^{P}-\underline{z}_{L}= & \frac{\left(1-z_{H}\right) n(n-1)((n+1) \gamma-n)\left((n+1)^{2} \gamma-n\right)}{\gamma(n+1) \Gamma}>0, \\
& \text { where } \Gamma \equiv\left[n^{2}(1-n)+n^{3}(n+1)^{2} \gamma-(n+1)^{3}\left(2 n^{2}+1\right) \gamma^{2}+(n+1)^{5} \gamma^{3}\right],
\end{aligned}
$$

for any $\gamma \geq 1$ and $n>1$, which proves the proposition (and also the nonemptiness of $Z^{x}$ and $Z^{P}$.

Q.E.D.

Proof of Proposition 6 Differentiating $p^{E}$ with respect to $n$, we have

$$
\frac{\partial p^{E}}{\partial n}=-\frac{\gamma\left[(n+1)^{2}\left(1-2 z_{H}+z_{L}\right) \gamma-\left(1-z_{H}\right) n^{2}+\left(z_{H}-z_{L}\right)\right]}{\left((n+1)^{2} \gamma-n\right)^{2}} .
$$

For $z_{L} \geq \underline{z}_{L}$, the partial derivative is maximized at $z_{L}=\underline{z}_{L}$. Substituting $z_{L}=\underline{z}_{L}$ into the partial derivative, we have

$$
\left.\frac{\partial p^{E}}{\partial n}\right|_{z_{L}=\underline{z}_{L}}=-\frac{1-z_{H}}{(n+1)\left((n+1)^{2} \gamma-n\right)}<0 .
$$

Therefore, $p^{E}$ is decreasing in $n$.

Q.E.D.

Proof of Proposition 7 (i) From (10), we have

$$
\begin{aligned}
& \frac{\partial Q_{-1}^{E}}{\partial n}=\gamma \times\left\{\frac{((n+1) \gamma-n)\left(2(n+1)^{2} \gamma-\left(n^{2}+1\right)\right)}{((n+1) \gamma-n)^{2}\left((n+1)^{2} \gamma-n\right)^{2}}\right. \\
& +\frac{\left[n^{2}\left(n^{2}+1\right)-n(n+1)\left(5 n^{2}+n+4\right) \gamma+(n+1)^{2}\left(7 n^{2}+6 n+3\right) \gamma^{2}-4(n+1)^{4} \gamma^{3}\right] z_{H}}{((n+1) \gamma-n)^{2}\left((n+1)^{2} \gamma-n\right)^{2}} \\
& \left.+\frac{(n+1) \gamma\left[n\left(n^{2}-n+2\right)-2(n+1)\left(n^{2}+n+1\right) \gamma+2(n+1)^{3} \gamma^{2}\right] z_{L}}{((n+1) \gamma-n)^{2}\left((n+1)^{2} \gamma-n\right)^{2}}\right\}
\end{aligned}
$$

This is positive if and only if

$$
\begin{aligned}
z_{L}<\frac{((n+1) \gamma-n)^{2}\left(2(n+1)^{2} \gamma-\left(n^{2}+1\right)\right)}{(n+1) \gamma\left[n\left(n^{2}-n+2\right)-2(n+1)\left(n^{2}+n+1\right) \gamma+2(n+1)^{3} \gamma^{2}\right]} \\
+\left[\frac{\left[-n^{2}\left(n^{2}+1\right)+n(n+1)\left(5 n^{2}+n+4\right) \gamma\right] z_{H}}{(n+1) \gamma\left[n\left(n^{2}-n+2\right)-2(n+1)\left(n^{2}+n+1\right) \gamma+2(n+1)^{3} \gamma^{2}\right]}\right. \\
\left.\quad+\frac{\left[-(n+1)^{2}\left(7 n^{2}+6 n+3\right) \gamma^{2}+4(n+1)^{4} \gamma^{3}\right] z_{H}}{(n+1) \gamma\left[n\left(n^{2}-n+2\right)-2(n+1)\left(n^{2}+n+1\right) \gamma+2(n+1)^{3} \gamma^{2}\right]}\right] \equiv z_{L}^{Q} .
\end{aligned}
$$


For the nonemptiness, see the next part (ii) of this proof.

(ii) With some algebra we obtain

$$
\begin{aligned}
z_{L}^{x}-z_{L}^{Q}= & \frac{2\left(1-z_{H}\right)((n+1) \gamma-n)^{2}\left((n+1)^{2} \gamma-n\right)^{2}\left((n+1)^{2} \gamma-\left(n^{2}+1\right)\right)}{n(n+1) \gamma\left[2 n-(n+2)(n+1)^{2} \gamma+2(n+1)^{3} \gamma^{2}\right] H^{\prime}}>0, \\
z_{L}^{Q}-z_{L}^{P}= & \frac{\left(1-z_{H}\right)(n-1)((n+1) \gamma-n)^{2}\left((n+1)^{2} \gamma-n\right)^{2}\left((n+1)^{2} \gamma-\left(n^{2}+1\right)\right)}{\gamma(n+1) H H^{\prime}}>0, \\
& \text { where } H=\left[n^{2}(1-n)+n^{3}(n+1)^{2} \gamma-(n+1)^{3}\left(2 n^{2}+1\right) \gamma^{2}+(n+1)^{5} \gamma^{3}\right], \\
& H^{\prime} \equiv\left[n\left(n^{2}-n+2\right)-2(n+1)\left(n^{2}+n+1\right) \gamma+2(n+1)^{3} \gamma^{2}\right],
\end{aligned}
$$

which proves the proposition.

Q.E.D. 


\section{References}

Aghion, P., Bloom, N., Blundell, R., Griffith, R. and Howitt, P., 2005. Competition and innovation: an inverted-U relationship. Quarterly Journal of Economics 120(2), 701728.

Aghion, P., Griffith, R., 2005. Competition and growth: reconciling theory and evidence. Cambridge, MA: MIT Press.

Allen, R.C., 1983. Collective invention. Journal of Economic Behavior and Organization $4(1), 1-24$.

Anton, J.J., Yao, D.A., 2004. Little patents and big secrets: managing intellectual property. RAND Journal of Economics 35(1), 1-22.

Ashiya, M., 2000. Weak entrants are welcome. International Journal of Industrial Organization 18(6), 975-984.

Bergstrom, T.C., Varian, H.R., 1985. Two remarks on Cournot equilibria. Economics Letters 19(1), 5-8.

Brander, J.A., Spencer, B.J., 1983. Strategic commitment with R\&D: the symmetric case. Bell Journal of Economics 14(1), 225-235.

Chen, Y., Riordan, M.H., 2007. Price and variety in the spokes model. Economic Journal $117(7), 897-921$.

Coughlan, A.T., Soberman, D.A., 2005. Strategic segmentation using outlet malls. International Journal of Research in Marketing 22(1), 61-86.

Creane, A., Konishi, H., 2009. The unilateral incentives for technology transfers: Predation (and deterrence) by proxy. International Journal of Industrial Organization 27(3), $379-389$.

d'Aspremont, C., Jacquemin, A., 1988. Cooperative and noncooperative R\&D in duopoly with spillovers. American Economic Review 78(5), 1133-1137. 
Daughety, A. F., 1990. Beneficial concentration. American Economic Review 80(5), 12311237.

—., 2008. Cournot competition. in The New Palgrave Dictionary of Economics. Palgrave Macmillan.

Davidson, C., Mukherjee, A., 2007. Horizontal mergers with free entry. International Journal of Industrial Organization 25(1), 157-172.

Etro, F., 2004. Innovation by leaders. Economic Journal 114(4), 281-303.

—_, 2006. Aggressive leaders. RAND Journal of Economics 37(1), 146-154.

—., 2007. Competition, Innovation, and Antitrust: A Theory of Market Leaders and Its Policy Implications. Springer: New York.

—_. 2008. Stackelberg competition with endogenous entry. Economic Journal 118(8), $1670-1697$.

Ino, H., Kawamori, T., 2009. Oligopoly with a large number of competitors: asymmetric limit result. Economic Theory 39(2), 331-352.

Ishibashi, I., Matsushima, N., 2009. The existence of low-end firms may help high-end firms. Marketing Science. 28(1), 136-147.

Kitahara, M., Matsumura, T., 2006. Realized cost based subsidies for strategic R\&D investments with ex ante and ex post asymmetries. Japanese Economic Review 57(3), $438-448$.

Lahiri, S., Ono, Y., 1988. Helping minor firms reduces welfare. Economic Journal 98(393), 1199-1202.

Lahiri, S., Ono, Y., 1999. R\&D subsidies under asymmetric duopoly: a note. Japanese Economic Review 50(1), 104-111.

Mansfield, E., 1986. Patents and innovation: an empirical study. Management Science $32(2), 173-181$. 
Mukherjee, A., Broll, U. and Mukherjee, S., 2009. The welfare effects of entry: the role of the input market. Journal of Economics 98(3), 189-201.

Mukherjee, A., Zhao, L., 2009. Profit raising entry. Journal of Industrial Economics 57(4), $870-870$.

Naylor, R. A., 2002. Industry profits and competition under bilateral oligopoly. Economics Letters 77(2), 169-175.

Nevins, A., 1954. FORD: The Times, the Man, the Company. New York: Charles Scribner's Sons.

Pénin, J., 2007. Open knowledge disclosure: an overview of the evidence and economic motivations. Journal of Economic Surveys 21(2), 326-347.

Salant, S.W., Shaffer, G., 1999. Unequal treatment of identical agents in Cournot equilibrium. American Economic Review 89(3), 585-604.

Schrader, S., 1991. Informal technology transfer between firms: cooperation through information trading. Research Policy 20(2), 153-170.

Spence, M., 1984. Cost reduction, competition, and industry performance. Econometrica 52(1), 101-121.

Suzumura, K., 1992. Cooperative and non-cooperative R\&D in an oligopoly with spillovers. American Economic Review 82(5), 1307-1320.

Tyagi, R., 1999. On the effects of downstream entry. Management Science 45(1), 59-73.

Vives, X., 2008. Innovation and competitive pressure. Journal of Industrial Economics 56(3), 419-469.

von Hippel, E., 1988. The Source of Innovation. New York: Oxford University Press.

Zhou, W., 2009. Innovation, imitation and competition. B.E. Journal of Economic Analysis 6 Policy 9(1) (Topics), Article 27. 

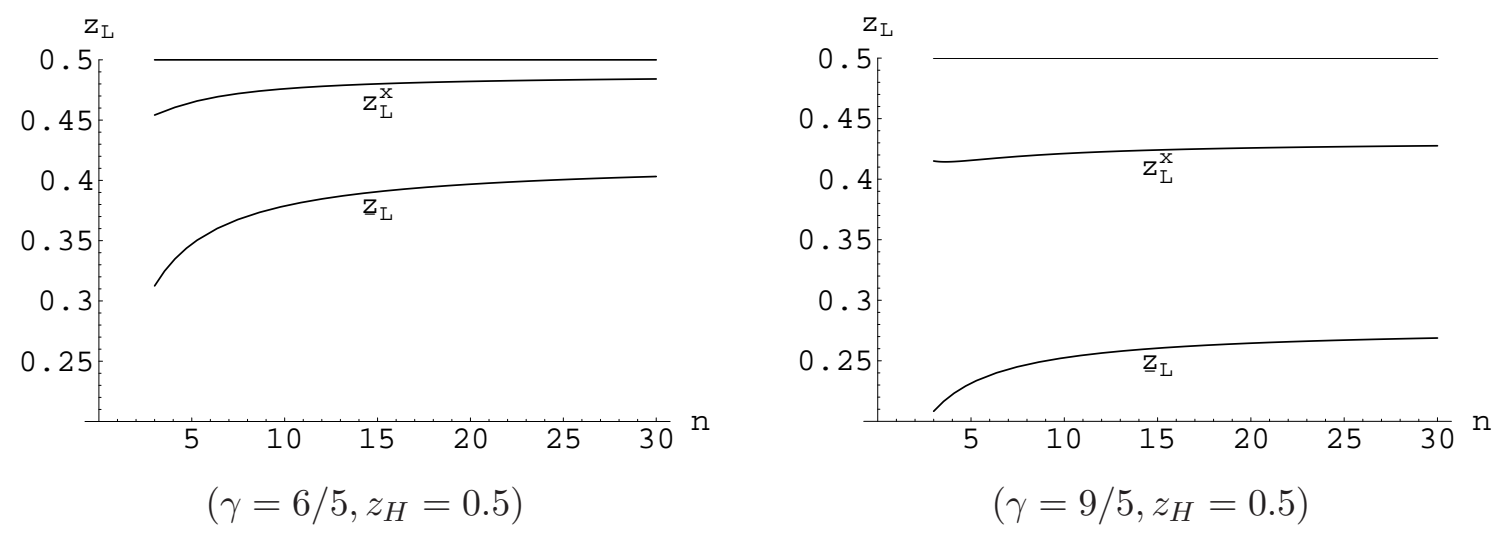

Figure 1: The range of $z_{L}$ for which an entry stimulates the low-cost firm's investment $\left(\partial x_{1} / \partial n>0\right)$. 

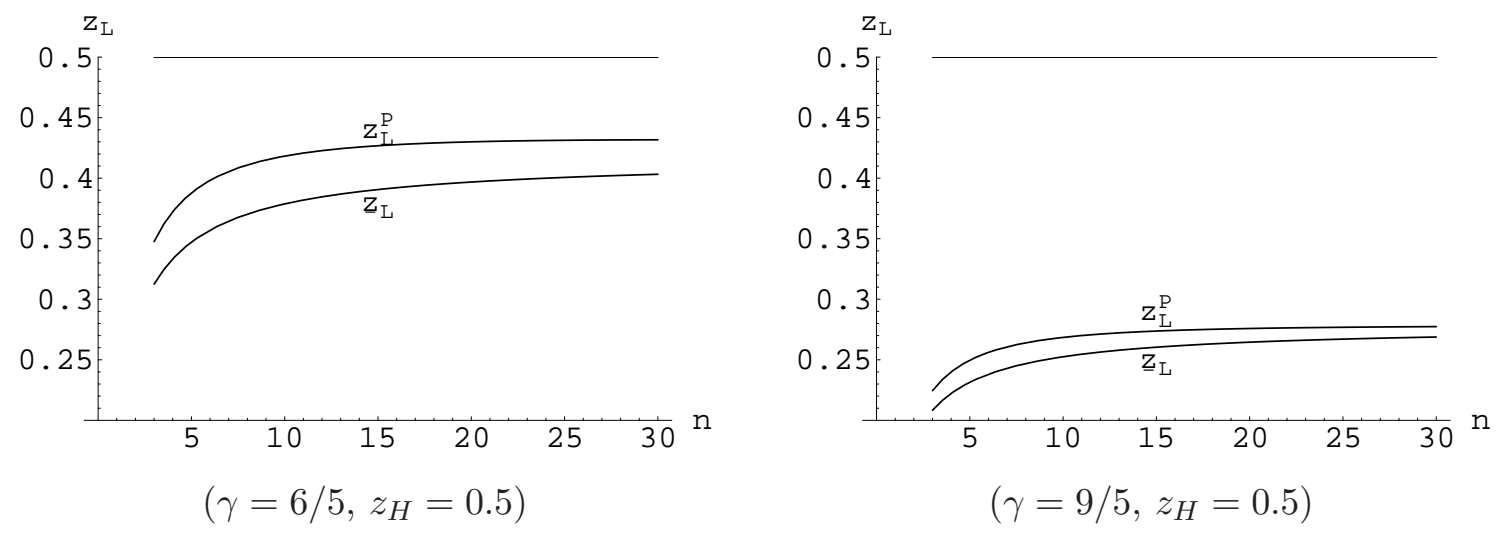

Figure 2: The range of $z_{L}$ for which an entry raises the low-cost firm's profit $\left(\partial \Pi_{1} / \partial n>0\right)$. 


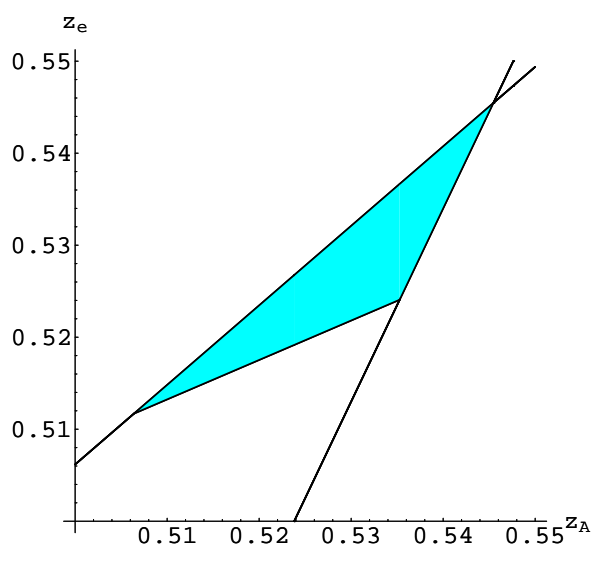

(a) $n=8$

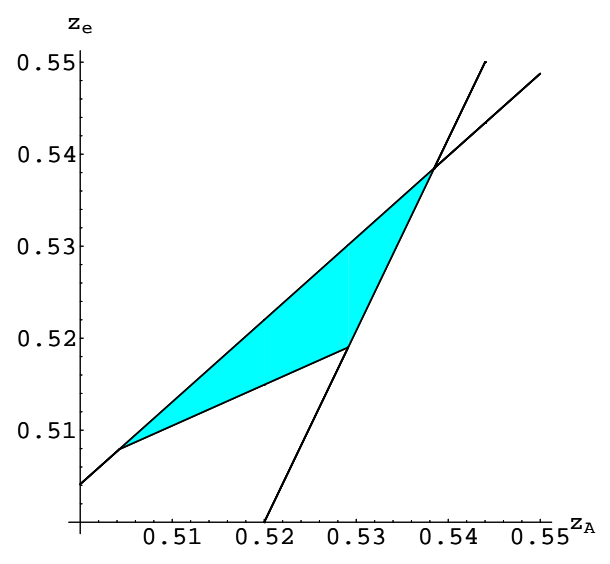

(b) $n=10$

$$
\left(a=1, z_{L}=0.5, \gamma=1\right)
$$

Figure 3: The condition under which an entry raises the low-cost firm's profit. $\left(z_{A}=\sum_{i=2}^{n} z_{i} /(n-1), z_{e}\right.$ : the entrant's ex ante marginal cost) 

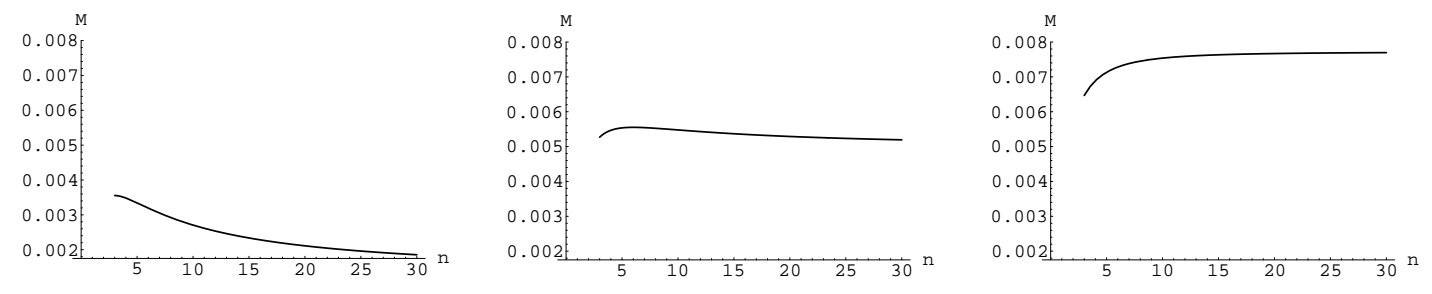

$$
\left(z_{L}=0.4, \gamma=10\right)
$$

$$
\left(z_{L}=3 / 10, \gamma=10\right)
$$

$$
\left(z_{L}=0.25, \gamma=10\right)
$$
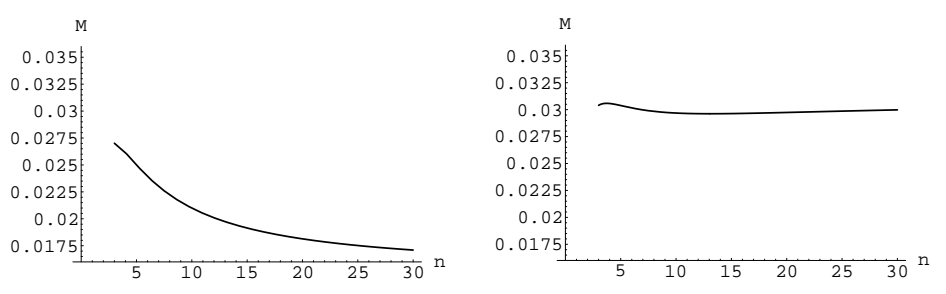

$$
\left(z_{L}=0.45, \gamma=3 / 2\right)
$$$$
\left(z_{L}=0.428, \gamma=3 / 2\right)
$$

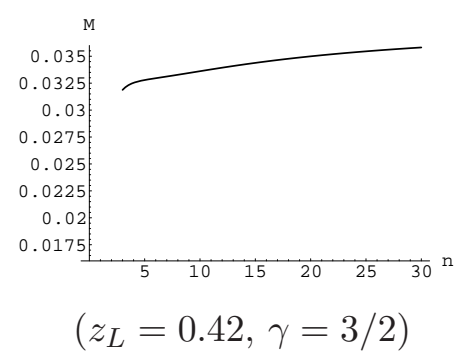

Figure 4: The relationship between $M$ and $n\left(z_{H}=0.5\right)$. 


\section{Appendix (not for publication)}

The profit of firm $i$ is (see (6)),

$$
\pi_{i}\left(n, \mathbf{z} ; z_{i}\right)=\left(\gamma^{2} \frac{(n+1)^{2}}{n^{2}}-\gamma\right)\left(x_{i}^{E}\left(n, \mathbf{z} ; z_{i}\right)\right)^{2} .
$$

It is then straightforward to obtain

$$
\begin{aligned}
\pi_{1}\left(n, \mathbf{z} ; z_{L}\right)= & \frac{\gamma\left((n+1)^{2} \gamma-n^{2}\right)}{((n+1) \gamma-n)^{2}\left((n+1)^{2} \gamma-n\right)^{2}} \times \\
& {\left[(n+1) \gamma-n+(n+1) \gamma \sum_{j \neq 1}^{n} z_{j}-n((n+1) \gamma-1) z_{L}\right]^{2}, } \\
\pi_{1}\left(n+1, \mathbf{z}^{\prime} ; z_{L}\right)= & \frac{\gamma\left((n+2)^{2} \gamma-(n+1)^{2}\right)}{((n+2) \gamma-(n+1))^{2}\left((n+2)^{2} \gamma-(n+1)\right)^{2}} \times \\
& {\left[(n+2) \gamma-(n+1)+(n+2) \gamma\left(z_{e}+\sum_{j \neq 1}^{n} z_{j}\right)-(n+1)((n+2) \gamma-1) z_{L}\right]^{2}, }
\end{aligned}
$$

where $\mathbf{z}^{\prime}=\left(\mathbf{z}, z_{e}\right)$. The entrant with $z_{e}$ increases the low-cost firm's profit if $\pi_{1}\left(n+1, \mathbf{z}^{\prime} ; z_{L}\right)>$ $\pi_{1}\left(n, \mathbf{z} ; z_{L}\right)$. The inequality is satisfied if and only if

$$
\begin{aligned}
& L z_{e}>-((n+1) \gamma-n)((n+2) \gamma-(n+1))\left(\left((n+1)^{2} \gamma-n\right) H-\left((n+2)^{2} \gamma-(n+1)\right)\right) \\
& -\gamma\left[(n+2)((n+1) \gamma-n)\left((n+1)^{2} \gamma-n\right) H\right. \\
& \left.\quad-(n+1)((n+2) \gamma-(n+1))\left((n+2)^{2} \gamma-(n+1)\right)\right] \sum_{j \neq 1}^{n} z_{j} \\
& +\gamma\left[(n+1)((n+1) \gamma-n)\left((n+1)^{2} \gamma-n\right)((n+2) \gamma-1) H\right. \\
& \left.\quad-n((n+2) \gamma-(n+1))\left((n+2)^{2} \gamma-(n+1)\right)((n+1) \gamma-1)\right] z_{L},
\end{aligned}
$$

where

$$
\begin{aligned}
H & \equiv \sqrt{\frac{(n+2)^{2} \gamma-(n+1)^{2}}{(n+1)^{2} \gamma-n^{2}}} \\
L & \equiv \gamma(n+2)((n+1) \gamma-n)\left((n+1)^{2} \gamma-n\right) H .
\end{aligned}
$$

This condition corresponds to the segmented line in Figure 3. 